\title{
Research on Chinese Urban Color Sorting Method Based on Quantitative Analysis
}

\author{
Wei SUN ${ }^{\text {a }}$, Xue-Dong XU \\ Changchun institute of Technology, Changchun, China \\ a64832294@qq.com, bxuxuedong1000@126.com
}

*Sun Wei

Keywords: Urban architecture color, quantitative analysis, Color database.

\begin{abstract}
Traditional urban architecture color is the carrier of urban characteristics and reflects the culture and the connotation of the city. In this paper, quantitative thinking and scheme of urban architecture color carding was put forward, and take the capital of the puppet period - Changchun city as an example, the urban construction color sample design and research method was studied, lay the foundation for the analysis of color by database technology.
\end{abstract}

\section{Introduction}

Cities are in the process of long-term development of culture, geography, climate, ethnic and other factors, can form a certain characteristics of urban color. Urban color in urban material space environment as the carrier, with building color as the main body, including roads, Bridges, public facilities, and other elements, which reflects the characteristics and connotation of the city. Urban construction, of which color is the traditional urban style and features of the main composition, has a strong regional identity utility [1].

To promote the process of rapid urbanization in China, many cities in the traditional color style were drowned by a lot of modern buildings; landscape formed in the history with unity and coordination of color is destroyed to be a state of disorder and confusion. Also urban architecture color tends to be the same [2]. Protection and continuation of urban architecture color features, showing regional culture connotation have become the urgent research subject with the urban development.

In recent years, many cities have realized the faults of traditional and modern color, and began by urban color planning and control, protection and continuation of the traditional color of the city. In Beijing, Tianjin, Harbin, Hangzhou, and other cities have to carry out the urban color planning and construction related activities [3]. But the city construction color research object more focused on building color, ignore the important factors such as traditional culture, times characteristics, is a single static. In means, more focused on the design principle and method of qualitative discussion, the lack of a scientific and quantitative research. This article takes Changchun city construction color, for example, the color with urban construction planning and control as the goal, from the folk culture, historical context and regional characteristics, study design urban architecture color sample library, and through the establishment of urban construction color research color information database. And research the color data analysis method, through the quantitative analysis of color data information, chromatography and color feature extraction inductive city, summarizes characteristics and status quo of application of Changchun city construction color, overall color planning and regional color and control for Changchun city provide advice and support.

\section{Changchun City Building Color Comb Analysis Idea}

\section{Changchun City Building Color Evolution}

In the primary stage of city at the end of the eighteenth century, the city construction color is greatly influenced by folk custom preferences. Northeast China is the birthplace of the Manchu, deeply affected on color application. The period of construction is given priority to with houses, 
color with yellow, green, red, green, grey etc give priority to color of color, composition is rich of natural materials, such as brick, stone, wood, clay, grass, etc., and has a variety of man-made color decoration, such as paint, glass, painting, etc. The overall effect is given priority to with grey color, match with colorful strong color ornament, primary and secondary and clear.

Man Tie affiliated to stage, at the end of 19th century Russia built near the train station of the European grid layout streets, yellow, white, red color and the construction of the Japanese "radial + checker-board" combination of ManTie accessorily area of Changchun city for the period on behalf of the color red series.

Established the puppet state in 1931 in Changchun, became the political and cultural center of the puppet. Japan hosted formulated the "dah sing Beijing urban planning", the old city, ManTie accessorily, commercial port and urban area unified planning. According to the function of land planning, a lot of yellow grey buildings, residential construction to build a series of office space design for administration of large public buildings, such as the eight most puppet, the puppet palace by the Japanese invaders, the state council, the puppet Kwantung army headquarters, etc., with distinctive color application characteristics of "xingya type" match well of Chinese and western architectural styles. The color of the typical buildings has become a symbol of Changchun history and culture, urban landscape architecture color characteristics and cultural temperament.

The fifties and sixties of the last century, as an important industrial base in Changchun, the newly built the First Auto Works, bus, and other industrial zone, the first car manufacturers blocks construction using the red walls and green tiles of architectural color, neighborhood units and local jewels around layout planning technique occupies a special position in the history of urban planning in our country.

Through the evolution course of the comb, it can be seen in Changchun city construction color feature is a blend of folk custom, history, geography, age, etc, rough analysis is given priority to with warm gray attune, can be used as cold and Changchun to adapt to the natural environment of the city.

After the reform and opening up in Changchun city center for the big transformation, built a large number of buildings with modern breath, many with high saturation and low lightness color materials, urban construction color showed a trend of diversification. Since there is no planning and control of urban architecture color, traditional color style not good inheritance, formed some regrets [4]. There is an urgent need to system of changchun city construction color research and comb, to control and guide of urban architecture color, in order to protect the urban historical context, the continuation of city memory.

\section{The Path of Quantitative Urban Architecture Color Carding}

This paper introduces urban architecture color computer data analysis method, from the perspective of history and urban development, in different period of Changchun city construction color as the research object, explore the formation and development of Changchun urban architecture color path. As shown in figure 1, by the color of a specific research method, to represent the characteristics of folk custom, history, geography, age monomer building as the main color samples, using database technology to establish the urban architectural color information database, and put forward the application of database in various color object value color characteristics analysis and chromatographic inductive method, realize the folk custom, history, geography, age, such as color feature extraction, to contemporary urban color planning design, the restoration of historic buildings and provides the reference for the protection of the historical context. 


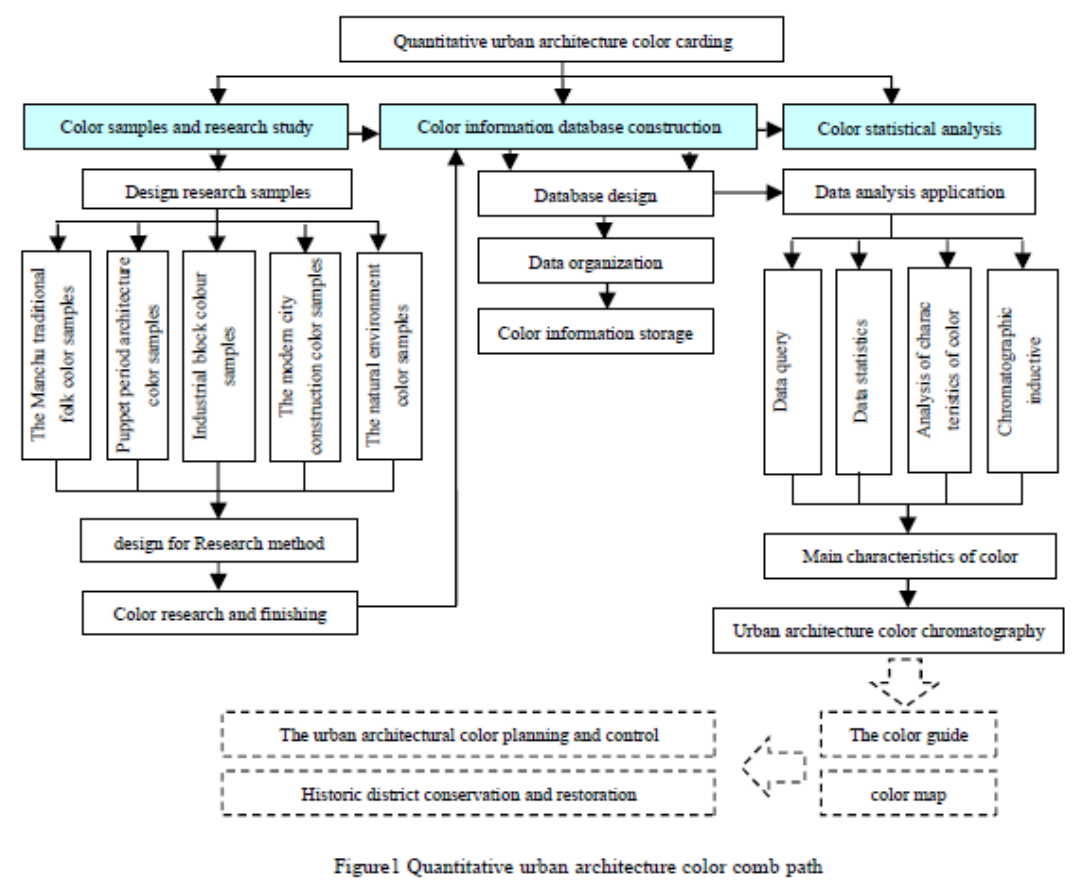

\section{City Construction Color Research Samples and Research Method}

\section{Design Color Sample of Urban Construction}

Along with the social development, humanities color factors on the impact of urban architecture color factors beyond geographical color. In the humanities color factors, traditional custom, our age, history has a profound effect on urban architecture color change. According to the folk custom, history, city construction research design color samples, each type of color with typical monomer structure and typical landscape color for samples.

Specific include: National traditional folk color samples: (1) the Manchu characteristics, local culture is the important aspect of urban building colors. The project will be from the application art and Manchu eight banners of Manchu dwellings color grading Angle research choose some typical monomer building as color sample. To folk blocks provide guidance, typical residential courtyard landscape color planning. Building color samples: (2) the puppet period in large public buildings and typical puppet local-style dwelling houses building as the object, design specific historical characteristics of the typical architectural color samples. Provide historical landscape planning and control of regional architectural color guide. (3) The new industrial form a complete set of residential building color samples: select the representative monomer building of First Auto Works history cultural zone as the color sample. In Changchun First Auto Works historical block, emerging industrial park, color planning to provide guidance.(4) the modern city landscape color samples: in view of the modern urban architecture color rich layers, from micro to macro perspective of different visual level of urban landscape colors, design of Changchun city. In recent years, new buildings color sample for administrative, commercial districts, development zones and other cities building color planning to provide guidance.

\section{Color research Methods}

Urban architecture color survey of affected by direct light color brightness and color temperature, color observation light source is given priority to with natural light, sample color change of light intensity and the composition of the sun's rays to turn the different visual effects [5]. Through experiment, different color temperature environment, observation of hue, grey value and color purity between 12 noon to ten to four remain basically stable. Therefore, this study will color observation time arranged between every day at four o 'clock at ten to ten. 
Observation distance also has impact on the investigation of color. Based on visual analysis, visual effect as the main standard, the environment the influence degree of the color of a person "field effect" can be divided into strong and balanced field games, weak and virtual four levels [6] for color research, "the strong field" (within $30 \mathrm{~m}$ ) and the "equilibrium" (30 $300 \mathrm{~m}$ ) distance is more appropriate, observation distance farther, color saturation decreases, but according to the color harmony theory, the balance between the colors better. Therefore, based on the "field" and "balanced" as the reference, selected the $1 \mathrm{~m}$ and $30 \mathrm{~m}$ and $100 \mathrm{~m}$ as the observation distance.

Choose CBCC Chinese architectural color card (1026) as a color mark tool, through field forensics, observation, record and analyze data related to the color of on the spot, at the same time with the method of the photography to record the sample color, on the basis of the photos are analyzed and summarized.

\section{Color Research and Application of Data}

At present, the author had partial organization school environment art majors students field survey on the status of Changchun city construction color, mainly including Changchun city Changjing road, four Chongqing road, Hongqi street, Guilin road business circle of billboards and public infrastructure, people's street, xi 'an road, the road of liberation and freedom of the road, and silicon valley street, Jilin DongCheng street road seven urban trunk road and prosperity, large construction street, the road on both sides of the main streets of article and so on more than 10 building color and adjacent area, has accumulated the color sample of more than 14000 copies. Have a detailed situation of Changchun city construction color. Later will analysis by means of computer, the specific methods as follows:

Color information database construction.

Based on the first phase of research sample color on Chinese color system, the GB/T15608-1995 standard into numerical information, using MySQL technology based color information database, detailed information stored color samples and color data values.

According to the analysis of the color information Based on data analysis technology, classification doesn't color information data within the database data query and intelligent analysis. Extracting main body color characteristics of the specific scope of data set, and chromatographic inductive figure out the main body color. Based on color research information and analysis summary for the overall evaluation to the types of color information, provide theoretical basis for the planning and control design of the color and the data base.

\section{Conclusion}

Many cities at home and abroad, to carry out the research and planning of urban architecture color is used more qualitative research methods, lack of quantitative statistics for color samples and intelligent analysis. In this paper, based on database technology of color analysis induction, feature extraction and chromatography make urban architecture color planning more scientific, quantitative data basis. This will scientific quantitative analysis and qualitative research method of combining the ease common history and traditional culture, the city landscape in urban construction, cultural landscape, the colors of Changchun city representative to be able to fully explore and scientific guidance control, thus protecting and Changchun strong regional features, the continuation of historical context and traditional style.

\section{Acknowledgement}

This research was financially supported by "The Jilin Science and Technology research Plan (No. 20150204041SF)"and”The Science and Technology Planning by Jilin Education Bureau(No. 2014[247])". 


\section{Reference}

[1] Wu Chen.The Variation and Inheriting of rchitectural Environment Color in Tianjin City [D].TianJin: Tianjin University.2010.

[2] Gao Mingyu,Ma Jinxiang.Research on Digital Environmental and Gamut--A Proposal of Digital Environmental Color Taking Qinhuangdao City's Building Color as an Example[J]. Journal of Northeast Agricultural University:Social Science Edition.2010,9(10):55-58.

[3] Jia Jingsheng. Penetrate into the Chinese Urban Color and Color Culture. Art \& Design. 2008, 32(179):77-79.

[4] SUN Wei,MO Wei.Urban Color Characteristics and Planning in ChangChun [J]. Journal of Jilin Architectural and Civil Engineering.2012, 29(5):30-32.

[5] LU Xu; YIN Jie; DING Yu; CHEN Peng. Investigation and Quantitative Analysis of Urban Color:A Case Study of ShenNan Avenue in ShenZhen[J].City Planning Review. 2010,34(12):88-92.

[6] QIU Qiang.Leading of Color Planning in General Urban Design:Example of Chongqing`s Urban Color Planning[J]. Modern Urban Research, 2006, 21(1):58-62. 